\title{
Erratum to: CASP3 and LDOC-1 gene expression in a patient with carcinoma in the hairy part of the head skin and Alzheimer disease
}

Michele Salemi • Pier Franco Soma •

Paolo Bosco - Enzo Vicari • Roberto Castiglione •

Aldo E. Calogero

Published online: 10 August 2013

(C) Japan Human Cell Society and Springer Japan 2013

Erratum to: Human Cell

DOI 10.1007/s13577-012-0052-5

The correct name of the co-author should be Roberto Castiglione, and not Castiglione Roberto as given in the original publication of the article.

The online version of the original article can be found under doi:10.1007/s13577-012-0052-5.

M. Salemi $(\bowtie) \cdot$ P. Bosco

Laboratory of Cytogenetics, Oasi Institute for Research on

Mental Retardation and Brain Aging, Troina, Italy

e-mail: micezia@tiscali.it

P. F. Soma

Plastic Surgery and Burns Centre, Cannizzaro Hospital, Catania,

Italy

E. Vicari · R. Castiglione - A. E. Calogero

Section of Endocrinology, Andrology and Internal Medicine,

Department of Internal Medicine and Systemic Diseases,

University of Catania, Catania, Italy 